director-general, Johann-Dietrich Wörner, said in January that the 2018 mission needed more funding to meet its launch target, and the agency is expected to ask member states for the missing few hundred million euros at a meeting in December. Success with ExoMars 2016 could help to persuade European leaders to contribute. Bridges says that most scientists will accept a delay as long as it means that all the instruments are on the craft and working.

Korablev's involvement with Mars missions has been an emotional roller coaster. He spent 10 years working on Russia's Mars 96 orbiter, which failed to leave near-Earth orbit. He was also involved in a sample-return mission to the Martian moon Phobos, which ran into problems, eventually crashing in the Pacific Ocean in 2012. "We put a great effort into ExoMars", he says. "I almost don't dare to say any words." -

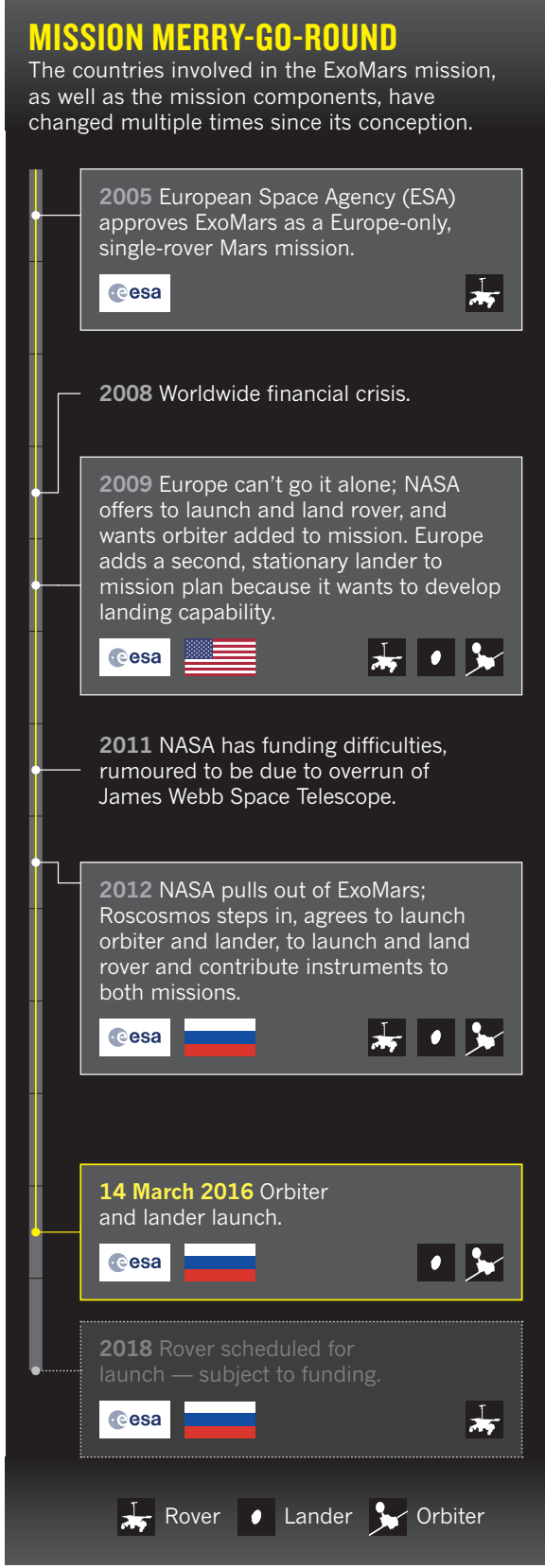

PLANETARY SCIENCE

\section{NASA Mars woes could delay missions}

\section{BY DEVIN POWELL}

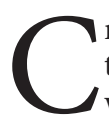
racks in an instrument designed to detect earthquakes on Mars will add roughly US\$150 million to the price tag of InSight, NASA's next mission to the red planet. But the agency said on 9 March that it still intends to fly the spacecraft, raising questions about how the unexpected expense will affect other planetary missions in development.

Although InSight's launch - originally scheduled for this month - is now slated for May 2018, it is not clear whether the spacecraft's faulty seismometer will be ready in time. InSight seeks to investigate Mars's interior by measuring seismic activity, as well as the heat that is escaping from the planet and the movement of its surface.

"We're really grateful that NASA has recognized the value of science we're going to do and agreed to give us a chance to try it again," says InSight's principal investigator, Bruce Banerdt, who works at NASA's Jet Propulsion Laboratory (JPL) in Pasadena, California.

The spacecraft was developed as part of NASA's Discovery Program, which funds small, quick-turnaround missions whose costs are capped at $\$ 450$ million. Five proposed missions are currently vying for a chance to launch in the early 2020s. These include a trip to Jupiter's Trojan asteroids, two missions to Venus and a camera that would detect near-Earth objects.

"NASA has been trying to choose two missions out of this round instead of one, and the community's concern is that the likelihood of that happening might be falling," says Linda Elkins-Tanton, a planetary scientist at Arizona State University in Tempe and principal investigator of a proposed mission to the asteroid Psyche.

Jim Green, director of NASA's planetaryscience division in Washington DC, says that budget details and consequences to other planetary missions will be worked out by August. "Our ability to select at least one Discovery mission in December is expected to be unaffected," he says.

Then there is the matter of whether InSight's troubled seismometer, which was developed by a global collaboration led by the Paris Institute of Earth Physics, can be repaired.

Banerdt says that Sodern, the French company subcontracted to build a vacuum container to enclose the seismometer's sensors, did not detect any problems with connectors that are supposed to seal wires leading out of the vacuum housing. Only when the instrument was tested in frigid, Mars-like temperatures in December did cracks in those seals become apparent. The project team tried to patch the problem, but persistent leaks remained.

"It's very frustrating," says Banerdt. "I've been working on getting this kind of mission for more than 25 years, and everything else on the project was going really well."

\section{FUTURE FIX}

NASA has asked the JPL to craft a new, hardier vacuum chamber. The agency's French collaborators will test the chamber at their own expense. "Personally, I am relieved to know that JPL will be taking responsibility for the vacuum chamber," says Lisa Pratt, a biogeochemist at Indiana University Bloomington.

The Mars InSight team is now re-running landing simulations and recalculating orbits to account for the updated launch date.

Some wonder

"We're really
grateful that
NASA has
recognized the
value of science
we're going
to do."
whether the mistake could cause NASA to tighten the reins on future projects. The most recent call for Discovery mission proposals - made before the problem with InSight occurred - mandated that no more than one-third of instrument costs be spent on foreign sources.

"The word on the street is that NASA's a little more wary of collaborating with groups that they don't know so well or don't control directly," says Elkins-Tanton.

But Green argues that any nation trying to build a new instrument could have made this mistake. "This is the first time this type of instrument has been built to withstand harsh environmental conditions on another planet," he says. - 